\title{
$\begin{array}{ll}\text { Research Square } & \text { Preprints are preliminary reports that have not undergone peer review. } \\ \text { They should not be considered conclusive, used to inform clinical practice, } \\ \text { or referenced by the media as validated information }\end{array}$
}

\section{Point-of-Care Testing in Community Pharmacies: A Mixed-Methods Study on Users and Pharmacists' Facilitators and Barriers}

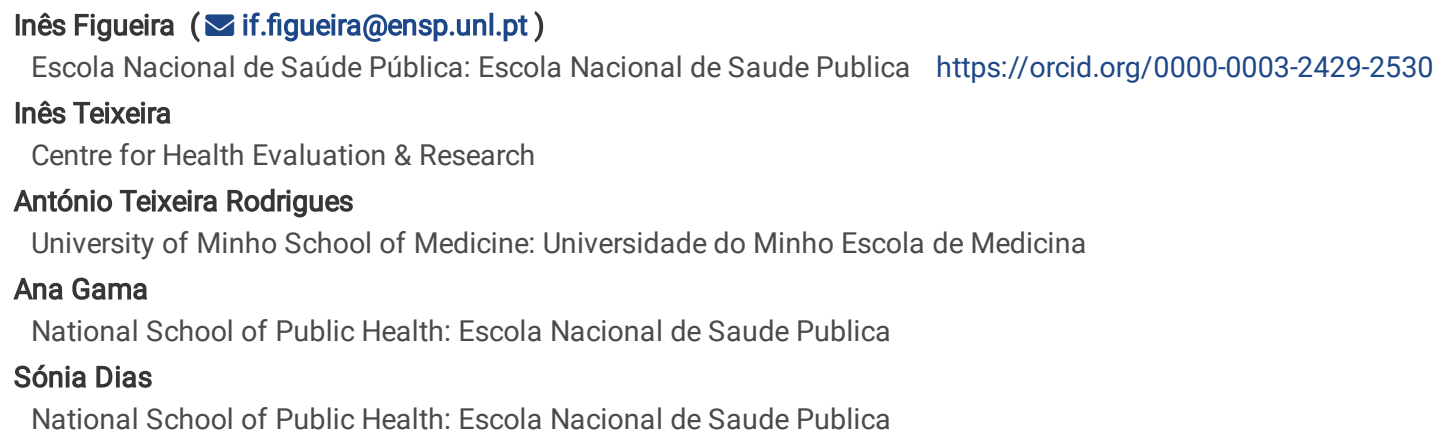

\section{Research Article}

Keywords: Point-of-care tests, Pharmacists, thematic content analysis

Posted Date: January 10th, 2022

DOI: https://doi.org/10.21203/rs.3.rs-1232244/v1

License: (c) (i) This work is licensed under a Creative Commons Attribution 4.0 International License. Read Full License 


\section{Abstract \\ Background}

Point-of-care tests can contribute to earlier diagnosis and treatment of infectious diseases with the potential to prevent chronic stages. As part of the Fast-Track Cities initiative, a pilot was initiated in community pharmacies in Portugal.

Aim

To characterize the individuals using point-of-care screening tests for human immunodeficiency virus, hepatitis $\mathrm{C}$ and hepatitis $\mathrm{B}$ virus infections in community pharmacies, their behaviours and motivations to perform the tests, as well as understand the facilitators and barriers from the perspectives of pharmacists.

\section{Method}

A mixed-methods study was conducted. A survey was applied to test users in pharmacies between May and December 2019, and three focus groups were conducted with pharmacists involved in the initiative. Qualitative data were analysed according to thematic content analysis.

\section{Results}

A total of 210 questionnaires were collected. Point-of-care tests users were predominantly male, mean age of 35 years, the majority were foreign-born and had higher education level. Almost half of the users were first time tested and the main reason for screening was unprotected intercourse. Pharmacists identified speed, confidentiality, counselling provided to users, pharmacists' initial training to perform the tests and trust in the pharmacist as facilitators of these tests. Stigma associated with infections, the procedure, logistical conditions and the referral process were considered as barriers.

\section{Conclusion}

Pharmacies are an effective screening site, with particular relevance for individuals who are first tested, heterosexuals and some migrants. Nevertheless, it is necessary to understand and reduce barriers and increase the support of specific groups.

\section{Impact Of Findings On Practice Statements}

- Point-of-care tests can contribute to earlier diagnosis and treatment of infectious diseases.

- Community pharmacies are an effective screening site and point-of-care tests availability in this setting seems to improve access.

- Main facilitators identified: speed, confidentiality and counselling provided by pharmacists.

- Main barriers reported: stigma, the procedure, logistical conditions and the referral process.

- Knowing the perspectives of main stakeholders is valuable to help define priorities and strategies to increase access to tests and could also encourage policymakers to provide funding.

\section{Introduction}

The human immunodeficiency virus (HIV), the hepatitis $\mathrm{C}$ virus (HCV) and the hepatitis B virus (HBV) remain a major public health problem worldwide [1,2], imposing a severe economic burden [3,4]. In 2020, almost 38 million people were living with HIV [5], 296 million people with chronic HBV infection and 58 with HCV [6]. In Portugal, the national prevalence of HIV was estimated in $0.40 \%$, and $1.45 \%$ and $0.54 \%$ for HBV and HCV, respectively [7,8]. Coinfection is frequent, with $7.4 \%$ HIV-HBV, and $6.2 \%$ HIV-HCV [4].

In Europe, 15\% of people living with HIV are undiagnosed [9], above the $10 \%$ targeted [10]. Late diagnosis remains a problem: approximately one quarter of people diagnosed between 2014 and 2016 were at an advanced stage of infection [11]. In Portugal, 90.3\% of people with the infection have already been diagnosed, $91.3 \%$ of diagnosed patients are undergoing treatment and $88.2 \%$ had the virus suppressed [12]. There is no available data on prevalence of undiagnosed HBV and HCV cases, but it is about 7\% for HIV, with the highest rate for heterosexual males (13.1\%) and the lowest for people who inject drugs (1.4\%) [7]. Screening is the main strategy to early detect these infections, enabling early treatment, reducing the risk of transmission, the progression to chronic stages and mortality associated with infections, but also contributing to the adoption of preventive behaviours due to the awareness and information given during the tests $[13,14]$.

International guidelines recommend different types of screening tests such as point-of-care (POC) tests [15,16], with many benefits, as requiring small samples of body fluids, taking short time, being easily performed by trained professionals, with a highly acceptable collection process to users, and provided in several settings, allowing to engage hard-to-reach populations in remote areas [17]. These tests are "affordable, sensitive, specific, user- 
friendly, rapid and robust, equipment-free and deliverable to end-users". At the community level, pharmacies have been a setting for POC HIV tests in many countries such as USA, Canada, England, Netherlands, Spain and Portugal [18-22].

Portugal has set early identification and diagnosis of HIV, HCV and HBV infections as a national priority, with tests being available at the primary health care centres, hospitals and civil society organizations [7]. In 2017, Portugal joined the Fast-Track Cities international initiative to ending the AIDS epidemic by 2030 [23]. Since August 2018, screening settings were extended to clinical laboratories and community pharmacies [24], which started performing POC tests for these infections under a pilot initiated in October 2018, as part of the initiative, in the Municipality of Cascais, region that presents a high prevalence of these infections.

A systematic review concluded that community pharmacies can conduct POC tests with satisfactory quality and effectiveness [25]. Further, several studies suggest that this setting is a feasible complementary approach and have shown that groups with higher risk of infection and groups with lower adherence to screenings prefer pharmacies to perform the tests [26-28].

Nevertheless, there are challenges regarding the implementation of screening tests in community pharmacies, to understand the barriers and facilitators of this type of service, as well as adherence to confirmatory tests and treatment $[20,29,30]$.

\section{Aim}

To characterize the individuals having point-of-care tests for HIV, HCV and HBV in community pharmacies, their risk behaviours, and motivations to perform the tests, and to understand facilitators and barriers to screening in these settings from the perspectives of pharmacists.

\section{Ethics approval}

The study was approved by the Institute for Bioethics of the Catholic University of Portugal (IB-UCP) Ethics Committee (Report 05/2019 for the quantitative component and Report 01/2020 for the qualitative component), complying with the national ethical requirements and legal procedures, General Data Protection Regulation (GDPR). Informed consent was obtained from all participants.

\section{Method}

\section{Study design}

A mixed-methods study was conducted in the community pharmacies in Portugal, consisting of a survey among pharmacy users and focus groups with pharmacists.

The criteria for inclusion of pharmacies in the study were participating in the Fast-Track Cities initiative, having pharmacists specifically trained to this service, and having a specific room with sound and visual isolation that ensured user confidentiality and privacy. From a total of 41 pharmacies from Cascais municipality, 21 (51.2\%) participated in the initiative with 46 pharmacists.

\section{Survey}

A self-administered, voluntary, anonymous survey was carried out to characterize the users of POC tests for HIV, HCV and HBV infections, their behaviours, and motivations to perform the tests in the pharmacy.

The participants were adults (aged $\geq 18$ ) who performed at least one POC test upon request. Pharmacy users were excluded if they were on medication for HIV, HCV or HBV, or showed behavioural/psychiatric conditions that would make them unable to provide consent. Tests were voluntary, free of charge and users could choose which test(s) they wanted to do.

Data were collected between $4^{\text {th }}$ May and $31^{\text {st }}$ December 2019.

A pre-test was performed to validate the study procedures and evaluate the feasibility of the questionnaire. This step allowed to change domains and rectify errors such as omissions or ambiguities and identify aspects to improve the procedures implemented in pharmacies.

\section{Data analysis}

For the characterization of the users, the statistical analysis performed presented central tendency and dispersion measures for continuous variables, absolute and relative frequencies for categorical variables. To assess the association between sociodemographic factors, the adherence and motivations to perform the tests, the Chi-Square test was performed with a $95 \%$ confident interval $(95 \% \mathrm{Cl})$. Spearman's correlation coefficient was used to assess the relationship between the ordinal variables, also with a $95 \% \mathrm{Cl}$. Dancey and Reidy's criteria have been applied to assess the intensity of the associations [31]. All analyses were conducted in Statistical Package for the Social Sciences (SPSS, 26) software.

\section{Focus groups}

A qualitative, exploratory study using focus groups was carried out to further understand the characteristics of users as well as the facilitators and barriers from the perspectives of pharmacists who perform the tests. Focus groups are a useful tool for this purpose and can be combined with 
quantitative methods [32]. Furthermore, this technique is common within research with healthcare professionals and was already used with pharmacists [33].

Pharmacists of all pharmacies in the project were invited, and a total of 15 participated in three focus groups, with six, four and five elements, respectively. The number of focus groups was established by the saturation criteria, until new information ceased to emerge [34].

Due to the COVID-19 pandemic, only the first focus group occurred in person. The following sessions took place online via Zoom platform. Focus groups were conducted by a moderator and a co-moderator, members of the research team. Participants gave their written or verbal consent for focus groups and were asked for permission to have the session recorded in audio, as it allows to ensure the quality of transcription and data analysis. A semistructured guide was used to conduct the discussion and a pre-test was carried out to test the guide. Sessions occurred in March, May and June 2020 and took approximately 50 minutes each.

\section{Data analysis}

Data collected in focus groups were analysed according to thematic content analysis, which included pre-analysis, material exploration and treatment, inference and interpretation of the results [35]. Recordings were transcribed verbatim by the co-moderator and validated by the moderator. Themes emerged through the reading of the speech and were categorized according to semantic criteria.

\section{Results}

\section{Survey to point-of-care tests users:}

From the 21 participant pharmacies, 363 test users met the eligibility criteria and $57.9 \%(n=210)$ completed the questionnaire. A total of 393 tests were performed ( $52.7 \%$ HIV, $32.1 \% \mathrm{HCV}, 15.2 \% \mathrm{HBV}$ ) on 210 individuals, with mean age of 35 [SD=13] years, $63.8 \%$ were male and most users had completed a university degree $(63.8 \%)$ as observed in Table 1 . About $23 \%$ of the users were foreign-born. 
Table 1

Sociodemographic characterization of

\begin{tabular}{|ll|}
\hline point-of-care tests users at pharmacies \\
\hline Fender & $\mathbf{n}=\mathbf{2 1 0}(\%)$ \\
\hline Male & $76(36.2)$ \\
\hline Age (years) & $134(63.8)$ \\
\hline $18+$ & $\mathbf{n}=\mathbf{2 1 0}(\%)$ \\
\hline $20-24$ & $10(4.8)$ \\
\hline $25-29$ & $42(20.0)$ \\
\hline $30-39$ & $37(17.6)$ \\
\hline $40-49$ & $48(22.9)$ \\
\hline $50-59$ & $42(20.0)$ \\
\hline $60+$ & $21(10.0)$ \\
\hline Country of birth & $10(4.8)$ \\
\hline Portugal & $\mathbf{n}=\mathbf{2 0 6}(\%)$ \\
\hline Other European country & $159(77.2)$ \\
\hline African country & $17(8.3)$ \\
\hline American country & $20(9.7)$ \\
\hline Level of education & $\mathbf{n}=\mathbf{2 0 7}(\%)$ \\
\hline None & $0(0)$ \\
\hline $1^{\circ}$ school (4th grade) & $1(0.5)$ \\
\hline $2^{\circ}$ cycle (6th grade) & $5(2.4)$ \\
\hline $3^{\circ}$ cycle (9th grade) & $7(3.4)$ \\
\hline College or equivalent & $62(30.0)$ \\
\hline University & $132(63.8)$ \\
\hline
\end{tabular}

The results in Table 2 showed access to first-time test users ( $38.2 \% \mathrm{HIV}, 45.0 \% \mathrm{HCV}, 50.9 \% \mathrm{HBV})$. There was one test with reactive result for HIV representing a prevalence of $0.5 \%$ ( $0.3 \%$ of total HIV tests performed in the pharmacies). In the last 12 months, most respondents were tested for HIV (51.6\%) and HCV (50.8\%). In contrast, the majority of HBV users (65.2\%) were tested more than 12 months ago. None of these previous tests had a reactive result reported. 
Table 2

Point-of-care tests users and results by virus (HIV, HCV, HBV)

\begin{tabular}{|llll|}
\hline Tests' results & HIV $n=207(\%)$ & HCV $n=126(\%)$ & HBV n=60 (\%) \\
\hline Non-reactive, fulfil window period & $138(66.7)$ & $56(44.4)$ & $39(65.0)$ \\
\hline Non-reactive, does not fulfil window period & $66(31.9)$ & $69(54.8)$ & $20(33.3)$ \\
\hline Reactive & $1(0.5)$ & $0(0)$ & $0(0)$ \\
\hline Unknown result & $2(1.0)$ & $1(0.8)$ & $1(1.7)$ \\
\hline 1 st time tested & HIV $n=207(\%)$ & HCV $n=120(\%)$ & HBV $n=57(\%)$ \\
\hline Yes & $79(38.2)$ & $54(45.0)$ & $29(50.9)$ \\
\hline No & $128(61.8)$ & $66(55.0)$ & $28(49.1)$ \\
\hline Last time tested & HIV $n=124(\%)$ & HCV $n=59(\%)$ & HBV $n=23(\%)$ \\
\hline In the last 12 months & $64(51.6)$ & $30(50.8)$ & $8(34.8)$ \\
\hline More than 12 months ago & $60(48.4)$ & $29(49.2)$ & $15(65.2)$ \\
\hline Result of the last test performed & HIV $n=123(\%)$ & HCV $n=62(\%)$ & HBV $n=24(\%)$ \\
\hline Reactive, may be infected & $0(0)$ & $0(0)$ & $0(0)$ \\
\hline Non-reactive, should not be infected & $122(99.2)$ & $60(96.8)$ & $22(91.7)$ \\
\hline I do not know & $1(0.8)$ & $2(3.2)$ & $2(8.3)$ \\
\hline
\end{tabular}

Almost all participants (98.6\%) performed HIV test, $60.0 \%$ and $28.6 \%$ performed HCV and HBV test, respectively. Taking HIV and HCV tests together was the most common option (36.2\%).

The main reasons for taking the tests (Table 3) were unprotected intercourse (49.0\%), changed sexual partner (26.2\%) and never been tested (23.8\%).

Table 3

Reasons to take the test

\begin{tabular}{|c|c|}
\hline Reasons to take the test(s) & $\mathrm{n}=210(\%)^{1}$ \\
\hline I had unprotected sex & $103(49.0)$ \\
\hline I changed my sexual partner & $55(26.2)$ \\
\hline I had never taken the test & $50(23.8)$ \\
\hline I need to demonstrate that I am not infected & $42(20.0)$ \\
\hline Other & $21(10.0)$ \\
\hline I got tattoos and/or piercing & $11(5.2)$ \\
\hline I had sex with a person living with HIV / AIDS and/or Hepatitis C virus and/or Hepatitis B virus & $9(4.3)$ \\
\hline I was subjected to a transfusion of blood or blood products & $1(0.5)$ \\
\hline I had sexual intercourse in the context of using recreational drugs (e.g. Chemsex, party'n'play, etc.) & $0(0)$ \\
\hline I shared injection material & $0(0)$ \\
\hline Time since the most recent situation that led to test & $\mathrm{n}=126(\%)$ \\
\hline Less than 3 months ago & $56(44.4)$ \\
\hline Between 3 to 12 months & $60(47.6)$ \\
\hline More than a year ago & $10(7.9)$ \\
\hline
\end{tabular}

Regarding the choice of doing the test at the pharmacy over other testing sites (Figure 1), more than a half of respondents considered the 'Reduced waiting time', 'Service privacy' and 'Confidence in pharmacist advice and competence' to be extremely important. On the other hand, 'Lack of knowledge of other place to perform the test', 'Lack of willingness to go to other places', and 'Fear of discrimination in other place' were considered not important at all, being non differentiating factors.

As major risk factors $11.7 \%$ of users referred to have had intercourse with people of the same sex and $9.1 \%$ have ever been diagnosed with a sexually transmitted infection (Figure 2). 
Chi-square test analysis revealed some statistically significant associations. Uptake of POC tests' was greater in men from Portugal (82.4\%) and from other European countries (5.33\%) whereas women of other regions (14.7\% Africa; $13.3 \%$ America) comparatively to the opposite gender $(P=0.030, \mathrm{df}=3$ ). Concerning the reasons to take the test, no significant differences were found across age groups, except the reason having never been tested ( $\mathrm{P}=0.000$, $\mathrm{df}=6)$, which was more frequently reported by users between $18-24$ years $(48.0 \%)$ and the oldest users above 60 years (30.0\%). Most of the youngest users reported unprotected intercourse $(59.6 \%)(P=0.047, d f=6)$, and having intercourse with someone of the same sex was more frequent in men $(16.0 \%)$ $(P=0.013, d f=1)$.

Spearman's coefficient of correlation revealed a strong positive correlation between the pharmacy's setting factor to take the test 'I don't feel comfortable going to other health services' and the factor 'I am afraid of being discriminated against if I test elsewhere' $[\rho=0,816, p=0.000]$. Both had low levels of importance, which seems to suggest that although the choice of the screening site does not depend on these characteristics, compared to other sites, the pharmacy seems to be more appealing.

\section{Focus groups - Pharmacists' perspectives: Characteristics of the focus groups participants}

From the 15 pharmacists that participated in the focus groups, 9 performed tests, and 6 participated in the implementation of the project by coordinating the pharmacies or providing the initial training to pharmacists.

Most participants were female (73.3\%) and between 25 and 36 years old (46.7\%). 20\% of the pharmacists had $2-9$ years of working experience in pharmacies, and the majority performed POC tests for HIV, HCV and HBV (66.7\%) over 9-13 months (46.7\%).

Three main themes emerged from the thematic analysis: users' characterization, facilitators and barriers, and project implementation.

\section{Characteristics of the POC tests users}

According to pharmacists' experience and perception, the uptake to POC tests is higher in people who are unregular service users of the chosen pharmacy to perform the tests. Professionals also highlighted the tests request by migrant populations and people generally at greater risk of being infected, such as homosexuals.

On the other hand, some pharmacists referred that older people, especially men, as well as some of the most at-risk populations (e.g. IDU) adhere less to this service. The need to have at least 18 years to take the test was mentioned as a factor that could be a barrier because young people have multiple risk behaviours.

When asked about how users have known the project, pharmacists referred to social networks/internet and pharmacies' advertisement as main tools.

Globally, pharmacists have done a positive balance of users' receptivity and test demand.

\section{Facilitators:}

\section{Pharmacists' role}

Pharmacists perceived their role as one of the most important facilitators for POC test users, who value their position in the community, their expertise and technical skills to perform the tests.

Pharmacists expressed a positive assessment of the project's implementation and that they feel prepared to conduct the tests. Some participants revealed caution in ensuring that trained professionals are available for an extended time and the physical conditions to preserve confidentiality.

The motivation of pharmacists was a transversal theme for all focus groups, considering it an essential element of the project success.

\section{Pharmacy's facilities}

Pharmacy accessibility in terms of proximity and waiting time for the tests' attendance, were identified as a key enabler for users when compared to other screening sites.

In terms of facilities, the existence of a private area that assures confidentiality and anonymity and the fact that pharmacies have an inclusive environment and are a healthcare service, sometimes being the first contact with the health system, were also valued by users according to pharmacists.

Aspects such as long opening hours and availability of tests on weekends, tests' gratuity and their simple procedure are other facilitators

\section{Tests' procedures}

From pharmacists' perspective, the pre- and post-test counselling facilitate the performance of this service, being less difficult to transmit the results because users manage them in a better way and understand the procedure in case of a positive result.

The training that pharmacists received to perform the tests and having a procedure guide were also considered facilitators. Furthermore, the relationship with regular customers is seen as another facilitator because there is a greater receptiveness to the tests and the counselling provided.

Page $7 / 12$ 


\section{Barriers: \\ Pharmacy's facilities}

The most likely barrier for users' engagement to POC tests identified by pharmacists was related to the proximity of people that may recognise users when they are tested, which is often overcome by choosing a distant pharmacy.

Stigma

The existing stigma associated to HIV, HCV and HBV, which is transversal to all screening sites, also represents an obstacle for tests and referral uptake.

\section{Tests' procedures}

For pharmacists, the major perceived barrier of this new service was the procedure in terms of difficulty in collecting an adequate blood sample with the material that is provided, as well as the lack of psychologic training to provide the results, especially if the patient is infected.

The referral process was highlighted as another challenge because of its complexity and duration, which can lead to the non-confirmatory test uptake.

The lack of information regarding the users' continuum of care in other healthcare services after a reactive test is seen as a barrier because pharmacists remain without knowing if patients had a confirmatory test and initiated treatment.

The way how referral process is designed may be also a barrier for users, particularly for migrants who have more difficulty navigating through the health system.

Logistic conditions were also perceived barriers for pharmacists since screenings take a long time, particularly referencing, and the professionals need to coordinate this service in the pharmacy workflow.

The availability of other alternatives as the HIV self-test also seems to be a factor that reduces the uptake to POC tests in pharmacies.

In what concerns the COVID-19 pandemic, pharmacists reported difficulties performing this service and the impossibility of carrying it out during the lockdown.

\section{Suggestions:}

Pharmacists also highlighted as factors for the success of this project the way how the service is disseminated. They consider as valuable methods to improve the uptake to tests the reinforcement of the project's awareness and presenting advantages of the screenings. It was also highlighted the importance of identifying groups with less access and to extend the project to more pharmacies.

Thinking about extending the project to other regions, pharmacists underscored possible inequalities in access between rural and urban areas. Participants suggested a direct link to the hospital to simplify the referencing process. The accuracy of the tests was also mentioned as something that may influence tests uptake. The sustainability of the project was also emphasized in terms of costs and financing of the tests.

\section{Discussion}

As far as we know, this is the first study conducted in Portugal on the use of point-of-care tests for HIV, HCV and HBV in the community pharmacies setting, contributing to identify facilitators and barriers that are influencing the uptake and success of the screening tests and site.

As observed in previous studies, users looking for these tests are mainly men, with mean age of 35 years [20, 36] and have completed a secondary/equivalent or higher education level $[26,30,37]$. On the other hand, although most users were natives, a higher rate of uptake by migrants was observed comparatively to other research $[20,29]$.

The HIV test was the most requested POC test and in conjunction with the HCV test the most common choice, which is in line with evidence that the joint availability of several tests contributes to increased adherence to the HIV screening [37]. Of the 210 users tested, only one showed a reactive HIV result, a rate similar to the national prevalence of the infection (0.40\%) [7]. Most users were HBV tested for the first time, and for the HIV and the HCV tests the values were also high, demonstrating that the pharmacy is an appealing place for those who have never done the tests. As observed in other studies, having unprotected sex, changing sexual partners and never been tested were the main reasons that led to screenings, and having sex with people of the same sex was the most frequent risk behaviour $[29,38]$. This study showed that users under 18 years old, elder people, socially vulnerable groups (e.g.: less educated, some migrants), drug users (recreational or injectable) and people who identify themselves as transgenders may have difficulty adhering to the screening tests.

According to the literature $[18,36,39]$, and the study results, the proximity, rapidity, comfort, confidentiality and trust in pharmacists are some of the main facilitators to the users of POC tests in this setting. On the other hand, factors such as the lack of knowledge of other screening sites, not feeling comfortable going to other health services and the fear of being discriminated do not seem to be differentiating characteristics of the pharmacy. Further, the only strong correlation was observed between an unwillingness to go to other health services and the fear of being discriminated in another location. 
Both factors obtained low levels of importance, which suggest that although the choice of the screening site does not depend on these characteristics, compared to other settings, community pharmacies are more appealing.

In the pharmacists' perceptions, the stigma, the referencing process and the proximity to the pharmacy may represent barriers for users, although the latter factor can also act as a facilitator for accessibility. Literature also highlights the time needed to take the test and stigma as the main barriers for users $[26,40]$.

The counselling provided and the relationship with users seem to increase the receptivity to the information transmitted and positively influence the way users manage the tests results, facilitating pharmacists' performance of the service, as well as the initial training provided for the application of the screenings. However, the professionals identified the testing materials, the lack of knowledge about the continuity of the process, the logistical conditions that are required to pharmacies and the time spent performing the tests as barriers. Other studies also referred that balancing the time to perform the tests within the pharmacy workflow, fear of getting infected and remuneration for the tests are the main barriers [26, 30]. Additionally, there exists a latent and niche group of consumers interested in POC tests in community pharmacies, younger users and in general willing-to-pay more than the general population for this service [41].

Pharmacists highlighted the lack of funding and the need to create conditions to ensure project sustainability, because the number of tests performed in each site ranged, which suggests that the implementation of this service may not be realistic for all pharmacies [26]. The accuracy of the tests, as well as the way how the project is disseminated were also mentioned in focus groups and in the literature. Some professionals also referred that there may be currently an overuse of the tests since they are free, although no evidence has been found in this regard. Pharmacists reveal to recognize the importance of the project and to be motivated to perform the service, factors also described in literature as conditions for a greater project engagement and success.

As suggested by pharmacists and other studies [38, 42,43], interventions such as normalizing infections screenings, creating community partnerships with doctors and key informants from the least-adhering groups, reinforcing the project's visibility and the possibility of scheduling tests could contribute to the elimination of some of the identified barriers, increasing tests uptake.

\section{Limitations}

Pharmacies were located exclusively in the Municipality of Cascais, hence the results are not generalizable for all pharmacy users in the country. There may be also a potential selection bias since participants, for convenience in recruiting, may have different characteristics from the pharmacy users that were not recruited. There is a potential bias related to self-report information which can compromise data validity and could implicate measurement bias with misunderstanding of some questions, memory bias with temporal confusion regarding risk behaviours and previous tests, and Hawthorne effect, considering that questionnaire was applied in community pharmacies.

The method of online focus groups could also be a limitation since it implies the use of technological facilities/resources, a greater effort of the moderator to unify the group and is more difficult to analyse the non-verbal language. However, this method could facilitate participants' adherence, richer testimonies for being more informal and the organization took less time [44].

\section{Strengths}

Despite the limitations, focus groups are a powerful research tool within health care, particular in the areas of patient compliance, costumer behaviour, patient-provider collaboration, health literacy and disease management [24]. The transcription of the focus groups recorded, and the content analysis made by the moderator and co-moderator increased the study validity. The fact that this study used mixed methods allowed triangulation of data and consequently mitigated limitations of quantitative and qualitative components/elements, increasing its credibility.

This study offers insights to improve POC testing, showing satisfactory results by users, and sharing greater responsibility for the screening and patient's care with other health professionals. This contributes to early diagnoses but also to the adoption of preventive behaviours due to more information and awareness during the tests. Additionally, the results may encourage policy makers to invest in this area and to establish screening programs in the community pharmacies allowing a wider range.

\section{Conclusion}

The study revealed that performing point-of-care tests in the community pharmacies seems to improve the population's access with relevance for those who are first tested, heterosexuals and some migrants. Although it is necessary to understand and reduce barriers and promote POC tests uptake among specific groups, pharmacies proved to be a feasible complementary site for HIV, HCV, and HBV screenings.

This study offers important insights to enhance adherence to these tests in the future. These findings could also encourage policymakers to provide funding to extend the project to more pharmacies and to allow screening tests to a larger number of people.

Future studies should identify the reasons for refusal to participate, the difference in the tests' uptake between viruses and between pharmacies and determine the cost-effectiveness of these service.

The improvements of the screening tests in community pharmacies should include an easier linkage to confirmatory testing services and follow-up care, which are critical for patients' outcomes and to provide value to the healthcare system. 


\section{Declarations}

\section{Acknowledgements}

The authors wish to acknowledge all the community pharmacies and pharmacists who actively engaged in the Fast-Track Cities initiative and contribute to the project assessment.

\section{Funding}

The study was funded by the National Association of Pharmacies. The sponsor had no role in the study design; in the collection, analysis, and interpretation of the data; in the preparation, review, or approval of the manuscript.

\section{Conflicts of interests}

The National School of Public Health/CISP/CHRC researchers declare no conflicts of interest. CEFAR researchers declares a conflict of interest to the extent to which CEFAR is an Investigation Centre that integrates the Infosaúde - Innovation and Formation in Health Institute, of the National Association of Pharmacies.

\section{References}

1. European Centre for Disease Prevention and Control, World Health Organization. HIV/AIDS Surveillance in Europe 2020: 2019 data. Copenhagen: WHO Regional Office for Europe, 2021. ISBN 978-92-9498-527-9. https://data.europa.eu/doi/10.2900/073965.

2. Thomas DL. Global elimination of chronic hepatitis. N Engl J Med. 2019;380(21):2041-2050. doi:10.1056/NEJMra1810477.

3. Trapero-Bertran M, Oliva-Moreno J. Economic impact of HIV/AIDS: a systematic review in five European countries. Health Econ Rev. 2014;4(1):1-16. doi:10.1186/s13561-014-0015-5.

4. World Health Organization. Global Hepatitis Report 2017. 2017. ISBN 978-92-4-156545-5. https://apps.who.int/iris/bitstream/handle/10665/255016/9789241565455-eng.pdf.

5. UNAIDS. Fact sheet - Latest global and regional statistics on the status of the AIDS epidemic. https://www.unaids.org/en/resources/documents/2021/UNAIDS_FactSheet. Published 2021. Accessed 20.11.2021.

6. World Health Organization. Global Progress Report on HIV, Viral Hepatitis and Sexually Transmitted Infections, 2021. Accountability for the Global Health Sector Strategies 2016-2021: Actions for Impact. Geneva; 2021. ISBN 978-92-4-002707-7. https://www.who.int/publications/i/item/9789240027077.

7. Directorate-General of Health/ The Doctor Ricardo Jorge National Health Institute. HIV and AIDS infection in Portugal - 2020. Lisboa; 2020. ISBN 978989-8794-76-5. http://repositorio.insa.pt/bitstream/10400.18/7243/1/DGS-INSA-RelatVIHSIDA-2020.pdf.

8. Carvalhana SC, Leitão J, Alves AC, Bourbon M, Cortez-Pinto H. Hepatitis B and C prevalence in Portugal: Disparity between the general population and high-risk groups. Eur J Gastroenterol Hepatol. 2016;28(6):640-644. doi:10.1097/MEG.0000000000000608.

9. European Centre for Disease Prevention and Control. The status of the HIV response in the European Union/European Economic Area, 2016. Stockholm. ECDC: 2017. doi: 10.2900/178785. https://www.ecdc.europa.eu/sites/default/files/media/en/publications/Publications/Status-of-HIVresponse-in-EU-EEA-2016-30-jan-2017.pdf.

10. UNAIDS. Fast-Track: Ending the AIDS Epidemic by 2030. 2014. doi:ISBN: 978-92-9253-063-1.

11. UNAIDS. Ending AIDS Progress towards the 90-90-90 Targets. AIDS Global AIDS Update. 2017. https://www.unaids.org/sites/default/files/media_asset/Global_AIDS_update_2017_en.pdf. Accessed 30.11.2021.

12. Directorate-General of Health. National Program for HIV, AIDS and Tuberculosis 2017. Lisboa: DGS. 2017:52. https://www.pnvihsida.dgs.pt/estudose-estatisticas111111/relatorios1/programa-nacional-para-a-infecao-vih-sida-e-tuberculose-2017-pdf.aspx. Accessed 30.11.2021.

13. Pedrana A, Howell J, Schröder S, et al. Eliminating Viral Hepatitis: The Investment Case. Doha, Qatar: World Innovation Summit for Health, 2018. ISBN: 978-1-912865-08-6. http://optimamodel.com/pubs/HCV\%202018.pdf. Accessed 30.11.2021.

14. Almeida LM De. From primordial to quaternary prevention. Prevenção em Saúde. 2005;23:91-96. http://dx.doi.org/10.1590/S0102$311 \times 2009000900015$.

15. World Health Organization. Consolidated Guidelines on HIV Testing Services for a Changing Epidemic. 2019. https://www.who.int/publications/i/item/WHO-CDS-HIV-19.31. Accessed 30.11.2021.

16. World Health Organization. WHO Guidelines on Hepatitis B and C Testing. Geneva: World Health Organization; 2017. PMID: 28742301. http://www.ncbi.nlm.nih.gov/pubmed/28742301.

17. Xiao Y, Thompson AJ, Howell J. Point-of-Care Tests for Hepatitis B: An Overview. Cells. 2020 Oct 2;9(10):2233. doi: 10.3390/cells9102233.

18. Dong BJ, Lopez M, Cocohoba J. Pharmacists performing hepatitis $\mathrm{C}$ antibody point-of-care screening in a community pharmacy: A pilot project. J Am Pharm Assoc. 2017;57(4):510-515.e2. doi:10.1016/j.japh.2017.04.463.

19. Kehrer JP, James DE. The Role of Pharmacists and Pharmacy Education in Point-of-Care Testing. Am J Pharm Educ. 2016 Oct 25;80(8):129. doi: 10.5688/ajpe808129. 
20. Fernández-Balbuena S, Belza MJ, Zulaica D, et al. Widening the Access to HIV Testing: The Contribution of Three In-Pharmacy Testing Programmes in Spain. Clark JL, ed. PLoS One. 2015;10(8):e0134631. doi:10.1371/journal.pone.0134631.

21. Weidle PJ, Lecher S, Botts LW, et al. HIV testing in community pharmacies and retail clinics: A model to expand access to screening for HIV infection. J Am Pharm Assoc. 2014;54(5):486-492. doi:10.1331/JAPhA.2014.14045.

22. Jones L, Pickering L, Sumnall H, Mcveigh J, Mark A, Bellis M. A review of the effectiveness and cost-effectiveness of needle and syringe programmes for injecting drug users. Liverpool, UK. 2008;(October):1-79. https://www.healthevidence.org/view-article.aspx?a=review-effectiveness-costeffectiveness-needle-syringe-programmes-injecting-drug-21010. Accessed 2.10.2021.

23. Ministry of Health. Fast-Track Cities - Cities on the Fast-Track to Ending the HIV Epidemic. 2017. https://www.sns.gov.pt/wpcontent/uploads/2017/11/Relatório-Cidades-na-via-rápida-para-acabar-com-a-epidemia-VIH-1.pdf.

24. Despacho no. 2522/2018, Diário da República, Série II, no.50. Performing point-of-care tests for screening HIV, HCV and HBV infections in community pharmacies and clinical pathology laboratories. 12 March 2018. https://files.dre.pt/2s/2018/03/050000000/0739407396.pdf.

25. Buss VH, Deeks LS, Shield A, Kosari S, Naunton M. Analytical quality and effectiveness of point-of-care testing in community pharmacies: A systematic literature review. Res Soc Adm Pharm. 2019;15(5):483-495. doi:10.1016/j.sapharm.2018.07.013.

26. Brewer A, Hanna C, Eckmann L, Schadler A, Divine H. Patient awareness, willingness, and barriers to point-of-care hepatitis $\mathrm{C}$ screening in community pharmacy. J Am Pharm Assoc. 2018;58(4):S69-S72.e1. doi:10.1016/j.japh.2018.04.031.

27. Fernández-Balbuena S, Belza MJ, Zulaica D, et al. Widening the access to HIV testing: The contribution of three in-pharmacy testing programmes in Spain. PLoS One. 2015;10(8):1-11. doi:10.1371/journal.pone.0134631.

28. Taheri L. Testing for hepatitis in pharmacies. Pharm Journal, 284 (7585), 51-52. 2010.

29. Amesty S, Crawford ND, Nandi V, et al. Evaluation of Pharmacy-Based HIV Testing in a High-Risk New York City Community. AIDS Patient Care STDS. 2015;29(8):437-444. doi:10.1089/apc.2015.0017.

30. Isho NY, Kachlic MD, Marcelo JC, Martin MT. Pharmacist-initiated hepatitis C virus screening in a community pharmacy to increase awareness and link to care at the medical center. J Am Pharm Assoc. 2017;57(3):S259-S264. doi:10.1016/j.japh.2017.03.006.

31. Dancey CP, Reidy J. Statistics Without Maths for Psychology. 4th ed. Prentice Hall 2007. ISBN-13: 978-0132051606.

32. Soares Silva I, Luísa Veloso A, Bernardo Keating J. Focus group: theoretical and methodological considerations. Rev Lusófona Educ 26 (175-190). 2014.

http://repositorium.sdum.uminho.pt/bitstream/1822/32357/1/Silva\%2c\%20Veloso\%20\%26\%20Keating\%20\%282014\%29_Focus\%20group_RLE.pdf.

33. Huston SA, Hobson EH. Using focus groups to inform pharmacy research. Res Soc Adm Pharm. 2008;4(3):186-205. doi:10.1016/j.sapharm.2007.09.001.

34. Saunders B, Sim J, Kingstone T, et al. Saturation in qualitative research: exploring its conceptualization and operationalization. Qual Quant. 2018;52(4):1893-1907. doi:10.1007/s11135-017-0574-8.

35. Bardin L. Análise de Conteúdo. Lisboa: Edições 70; 2006. ISBN: 9789724415062.

36. Gorostiza I, López de Landache IE, Braceras Izagirre L. HIV/AIDS screening program in community pharmacies in the Basque Country (Spain). Gac Sanit. 2013;27(2):164-166. doi:10.1016/j.gaceta.2012.02.010.

37. Crawford ND, Dean T, Rivera A V., et al. Pharmacy Intervention to Improve HIV Testing Uptake Using a Comprehensive Health Screening Approach. Public Health Rep. 2016;131(1_suppl):139-146. doi:10.1177/00333549161310S116.

38. Darin KM, Klepser ME, Klepser DE, et al. Pharmacist-provided rapid HIV testing in two community pharmacies. J Am Pharm Assoc. 2015;55(1):81-88. doi:10.1331/JAPhA.2015.14070.

39. Dugdale C, Zaller N, Bratberg J, Berk W, Flanigan T. Missed opportunities for HIV screening in pharmacies and retail clinics. J Manag Care Pharm. 2014;20(4):339-345. doi:10.18553/jmcp.2014.20.4.339.

40. Hepatities C Trust. Pharmacy-based testing for hepatitis B and hepatitis C. 2009. http://www.hcvaction.org.uk/sites/default/files/resources/Pharmacybased\%20testing\%20for\%20hepatitis\%20B\%20and\%20hepatitis\%20C\%20\%28hep\%20c\%20trust\%29.pdf. Accessed 20.11.2021.

41. Hohmeier KC, Loomis B, Gatwood J. Consumer perceptions of and willingness-to-pay for point-of-care testing services in the community pharmacy. Res Soc Adm Pharm. 2017;14(4):360-366. doi:10.1016/j.sapharm.2017.04.011.

42. SteltenpohI EA, Barry BK, Coley KC, McGivney MS, Olenak JL, Berenbrok LA. Point-of-Care Testing in Community Pharmacies: Keys to Success From Pennsylvania Pharmacists. J Pharm Pract. 2018;31(6):629-635. doi:10.1177/0897190017735243.

43. Centers for Disease Control and Prevention. Implementing HIV Testing in Nonclinical Settings: A Guide for HIV Testing Providers. CDC: Division of HIV/AIDS Prevention. 2016. https://www.cdc.gov/hiv/pdf/testing/CDC_HIV_Implementing_HIV_Testing_in_Nonclinical_Settings.pdf.

44. Stewart DW, Shamdasani P. Online Focus Groups. J Advert. 2017;46(1):48-60. doi:10.1080/00913367.2016.1252288.

\section{Figures}




\begin{tabular}{|c|c|c|c|}
\hline Reduced waiting time & $2,5 \quad 6,5$ & 32,0 & 59,0 \\
\hline Confidence in pharmacist advice and competence & $0,55,1$ & 43,1 & 51,3 \\
\hline
\end{tabular}

Figure 1

Evaluation of factors by POC tests users when choosing the screening site

Had sex with people of the same sex

Ever been diagnosed with a Sexually Transmitted Infection

Had sexual intercourse with a person living with HIV/AIDS and/or HepC and/or HepB

Ever been paid or paid to have sex Use injecting drugs

Identify themselves as transgender $\mathbf{0}$

$0 \%$

\section{1,7}

5,8

94,2

95,9

4,1

100

100

$40 \%$

$20 \%$

$\square$ Yes $\quad$ No

\begin{tabular}{|l|l|}
\hline 0 & \\
\hline 0 & 100
\end{tabular}

88,3

90,9

\section{Figure 2}

Factors associated with increased risk of HIV, HCV and HBV infection among community pharmacy POC test users 